\title{
Transcrição da tinta ao Braille: apontamentos de algumas diferenças semio-cognitivas
}

\author{
Transcription of ink print into braille: \\ note of some semio-cognitive differences
}

Daiana Zanelato dos Anjos ${ }^{1}$

Méricles Thadeu Moretti ${ }^{2}$

\begin{abstract}
Resumo
Preocupamo-nos, neste trabalho, com a aprendizagem matemática por estudantes cegos. Buscamos analisar duas ferramentas utilizadas em sala de aula para estes estudantes: o Livro Didático de Matemática em Braille (LDMB) e o Código Matemático Unificado (CMU) para a Língua Portuguesa. Os seguintes questionamentos foram o fio condutor no estudo da transcrição do livro didático impresso em tinta para o livro em Braille: em que condições esta transcrição é elaborada? Que diferenças semio-cognitivas importantes surgem? O que ocorre com as expressões matemáticas envolvidas? Apontaremos, neste estudo, diversas dificuldades de aprendizagem matemática que podem ter origem nessas transformações semióticas.
\end{abstract}

Palavras-chave: Educação inclusiva; Registros de representação semiótica; Livro Didático em Braille; Código Matemático Unificado.

\begin{abstract}
In this paper, we are concerned about Math learning by blind students. We aimed to analyze two tools used in the classroom with these students: the Math Textbook in Braille (Livro Didático de Matemática em Braille LDMB) and the Mathematical Unified Code (Código Matemático Unificado - CMU) to the Portuguese language. The following questions were the common thread in the study of the ink printed textbook transcription into the book in Braille: In what conditions does this transcription occur? What important semio-cognitive differences arise? What happens to the mathematical expressions, which are involved? In this study, we will point out various difficulties of Math learning that can come from these semiotic transformations.
\end{abstract}

Keywords: Inclusive education; Semiotic representation registers; Textbook in Braille; Mathematical Unified Code.

\section{Introdução}

A Educação Inclusiva, devido às leis e regulamentações que a fundamentam, passou a ser realidade em várias escolas brasileiras. Isso apesar das grandes dificuldades enfrentadas por todo o sistema de ensino, entre as quais, a preparação de professores, como apontado em Machado (2009, p. 11).

\footnotetext{
1 Mestre em Educação Científica e Tecnológica pela Universidade de Santa Catarina. Brasil. Email: daizanelato@gmail.com.

${ }^{2}$ Professor titular e voluntário da UFSC. Professor permanente do Programa de Pós-Graduação em Educação Científica e Tecnológica (PPGECT/UFSC). E-mail: mthmoretti@gmail.com. 
A existência da inclusão em escolas das redes públicas e particulares, justamente, tomou maior força a partir da Declaração de Salamanca (Unesco, 1994), que apresenta, entre outros princípios, a necessidade de acesso às escolas regulares pelas crianças com deficiência. Já em relação à formação de professores, citamos um impulso dado a partir da Lei $\mathrm{n}^{\circ}$ 9.394/96 (Lei de Diretrizes e Bases da Educação Nacional). Em seu 5 Capítulo, a LDB/96 responsabiliza o município pela implementação da educação inclusiva em todos os níveis de ensino, assim como assegurar professores de ensino regular capacitados para incluir os estudantes com deficiência em classes comuns.

Nas Diretrizes Curriculares Nacionais para a Educação Básica (Brasil, 2013), documento que foi disponibilizado nas escolas públicas de Educação Básica no decorrer do ano de 2015, consta a aprovação das Diretrizes Operacionais para Atendimento Educacional Especializado na Educação Básica, modalidade Educação Especial (Resolução no 4/2009) através do Parecer CNE/CEB n ${ }^{\circ} 13 / 2009$, que entre outras proposições estabelece como prioridade, a obrigatoriedade da matrícula de alunos com deficiência na escola comum do ensino regular e a formação de professores. $\mathrm{O}$ que mostra que permanece a preocupação em atender os estudantes com deficiência na rede regular em classes comuns, sendo essa uma área que devemos nos debruçar no intuito de elaborar estudos que possam mostrar caminhos para a educação desses estudantes. As pesquisas na temática do processo de ensino e aprendizagem de matemática, as inquietações geradas com a educação de estudantes cegos vêm crescendo também e alcançando resultados que já se mostram presentes em pesquisas como as de Fernandes e Healy (2007; 2010), Mello (2012), Anjos (2008; 2014; 2015) e Uliana (2013).

O Livro Didático de Matemática em Tinta (LDMT), do qual a transcrição para o Braille foi efetuada e utilizada neste trabalho, é um livro didático comum do Sistema de Ensino Positivo do $9^{\circ}$ ano do Ensino Fundamental destinado ao estudante que enxerga. $\mathrm{O}$ acesso aos materiais didáticos permitiu as análises elaboradas a partir das transcrições do LDMT para o Livro Didático de Matemática em Braille (LDMB) e do Código Matemático Unificado $(\mathrm{CMU})^{3}$. É importante destacar que a transcrição da tinta para o Braille é feita a partir do que aparece no livro em tinta, o livro em Braille não é pensado diretamente para o estudante cego.

Para apontar algumas diferenças semio-cognitivas importantes na transcrição do LDMT ao LDMB e CMU, as análises efetuadas, a seguir, fundamentarem-se na noção de registro de representação semiótica da teoria de aprendizagem semiótica em matemática de Duval (2003, 2004, 2011, 2012). Sob esta ótica semio-cognitiva, que possui elementos que

\footnotetext{
${ }^{3}$ Código Matemático Unificado para a Língua Portuguesa (CMU) é o documento oficial do MEC que oferece "opções para a representação de símbolos do sistema comum, até agora sem representação adequada no Sistema Braille" (Brasil, 2006, p. 15). Este material é utilizado por transcritores, professores, usuários e pessoas envolvidas com a educação de estudantes cegos, no intuito de elaborar textos e fazer transcrições de livros didáticos.

${ }^{4}$ A transcrição do Livro em tinta para o Livro em Braille é feita pelo CAP/Florianópolis.
} 
servem de base para a aprendizagem matemática em que a noesis só pode ser levada a cabo a partir da semiose, o presente artigo foi pensado. Os objetos matemáticos são ideais e só podem ser alcançados por meio de representações semióticas e, deste modo, pensamos que certas regras semióticas podem ser aplicadas ao aluno seja ele cego ou não. Grande parte desse estudo toma por base a dissertação de Anjos (2015). Estamos aprofundando discussões teóricas com o objetivo de apresentar alternativas semióticas a partir de um trabalho de observação, em andamento - tese de doutorado da primeira autora do presente trabalho - que trata da aprendizagem matemática por alunos cegos.

\section{Registros de Representação Semiótica: objeto, conteúdo e forma}

Destacaremos as características do que é registro em Duval para percebermos a importância e as diferenças quando da transcrição da tinta para o Braille.

Um registro possui forma, conteúdo em referência a um objeto matemático em se tratando de aprendizagem matemática. Assim, os registros "um", "6/6" e "50" possuem formas e conteúdos diferentes mesmo referindo-se ao mesmo objeto. Um muitos casos, basta que a forma da representação mude para o conteúdo também seja modificado.

Em relação ao conteúdo e a forma do registro, Duval (2004, p. 62-69; 2011, p. 21-39) inspirou-se no trabalho Ferdinand de Saussure (Saussure, 2008, p. 131) em seu cours de linguistique générale, publicado postumamente em 1916, com o signo linguístico que o define como uma entidade inseparável que põe em oposição o significado (um conceito) do significante (imagem acústica). Dos estudos de Saussure destacamos a importância dada ao sistema no qual o signo foi produzido:

(...) é uma grande confusão considerar um termo simplesmente como a união de certo som com um certo conceito. Defini-lo assim seria isolá-lo do sistema do qual ele faz parte; seria acreditar que é possível começar dos termos e construir o sistema fazendo a soma deles, quando pelo contrário, cumpre partir da totalidade solidária para obter, por análise, os elementos que encerra. (Saussure, 2008, p.132).

Nos trabalhos de Saussure não é aparente o papel do objeto de referência. Assim, Duval (2011, p. 21-32) busca, esse elemento, na definição de signo em Charles S. Peirce:

Um signo, ou representâmen, é aquilo que, sob certo aspecto ou modo, representa algo para alguém. Dirige-se a alguém, isto é, cria na mente da pessoa, um signo equivalente, ou talvez um signo mais desenvolvido. Ao signo assim criado denomino interpretante do primeiro signo. O signo representa alguma coisa, o seu objeto. Representa esse objeto não em todos os seus aspectos, mas com um tipo de ideia que eu, por vezes, denominei fundamento do representâmen. (Peirce, 2000, p. 46).

Tomando as ideias de Saussure (2008) e Peirce (2000), na Figura 1, a seguir, apresentamos um esquema do registro que leva em conta os polos constitutivos do registro de representação. 
DOI: http://dx.doi.org/10.20396/zet.v24i3.8648092

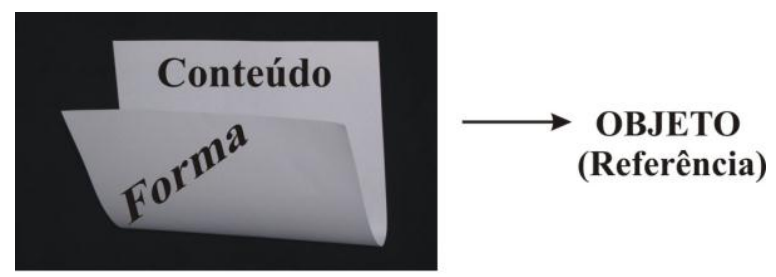

\section{REGISTRO}

Figura 1 - Esquema constitutivo do registro Fonte: Moretti e Thiel (2012, p. 383).

As transformações de registros podem ocorrer em um mesmo registro e em registros distintos. Essas operações são denominadas, respectivamente, tratamento e conversão. Quando fazemos a seguinte operação $\frac{1}{2}+\frac{3}{5}=\frac{5+6}{10}=\frac{11}{10}$, efetuamos um tratamento por que nos mantivemos no mesmo sistema semiótico. Mas, se fizermos a mudança $\frac{1}{2}+\frac{3}{5}=0,5+0,6$, produzimos conversão na transformação de $\frac{1}{2}+\frac{3}{5}$ em $0,5+0,6$ para, em seguida, operar um tratamento e obter o valor 1,1 .

$\mathrm{Na}$ conversão de registros de representação semiótica, entra em cena um fenômeno denominado não congruência semântica que estabelece o grau de transparência entre esses registros mantendo-se a mesma referência ao objeto matemático (Duval, 2004, p. 50-55). Assim, o " 1 " pode ser representado, por exemplo, pelos registros " $6 / 6$ " e " 5 ". Um estudante pode reconhecer os registros "um" e " 1 " como o mesmo objeto e não reconhecê-lo em " $6 / 6$ " ou " 5 ": houve mudanças de forma e, por consequência, os conteúdos mudam também. A análise de congruência passa, inicialmente, pelo reconhecimento das unidades significantes em cada sistema semiótico empregado e pela verificação de três critérios apontados por Duval (2004, p. 53), que são:

- possibilidade de uma congruência semântica dos elementos significantes;

- univocidade semântica terminal;

- ordem de arranjo das unidades que compõe cada uma das representações.

No $1^{\circ}$ critério, temos que identificar as unidades significantes em cada registro e verificar a correspondência entre elas; no $2^{\circ}$ critério, a condição é em relação às unidades de partida e de chegada, devendo existir uma unidade significante de partida para uma única unidade significante de chegada; finalmente, para o $3^{\circ}$ critério, devemos dispor a apresentação das unidades na mesma ordem entre os dois registros (Brandt e Moretti, 2013, p. 57-59).

No caso da transcrição para o Braille há, em algumas situações, mudanças drásticas na forma do registro: por exemplo, para uma paisagem no LDMT, o estudante cego tem acesso a uma descrição dessa paisagem no LDMB; para a soma de fração, como, por exemplo, $\frac{1}{2}+\frac{3}{5}$ 
aparece em Braille na seguinte forma em linha $(1 \div 2)+(3 \div 5)$ acrescido de vários outros caracteres próprios ao CMU.

$\mathrm{Na}$ transcrição da tinta para o Braille, a mudança de forma do signo pode vir acompanhada de um aumento significativo de caracteres. São estes dois aspectos fundamentais de mudança que levaremos em conta na discussão que se segue, guiados pelas questões seguintes: De que forma é feita a transcrição do LDMT e para o LDMB? O que acontece quando as transcrições feitas de um registro a outro envolvem expressões matemáticas? O modo como as transcrições são feitas pode influenciar a aprendizagem do estudante cego?

Quando realizamos a conversão entre registros, podemos trabalhar com três formas de conversão: a ilustração; a tradução; e a descrição. A ilustração é uma conversão de um registro linguístico para um registro figural. Descrição é a mudança do registro figural para o linguístico. Já a tradução é uma troca entre um registro linguístico de uma língua para outra língua.

A conversão ocorre entre representações oriundas de diferentes sistemas semióticos. Por essa razão, para podermos falar em conversão entre registros da escrita natural para o Braille, faremos uma confirmação que de fato o Braille é um sistema semiótico, uma língua. Para analisar esta condição do Sistema Braille como uma língua, levaremos em consideração o que nos aponta Duval (2004, p. 89) em relação ao cumprimento de quatro funções chamadas funções discursivas. Duval (2004), em seu estudo sobre os registros de representação semiótica, classifica a língua em dois grupos de funções totalmente diferentes: as metadiscursivas e as discursivas.

As funções metadiscursivas pertencem a qualquer sistema semiótico e são elas: comunicação, tratamento e objetivação. No entanto, para que um sistema semiótico seja considerado uma língua, ele deve possuir quatro funções discursivas, isto é, funções cognitivas que tornam possível um discurso: função referencial, função apofântica, função de expansão discursiva e função de reflexividade (Duval, 2004, p. 88-89). Nessa ordem, com essas funções, teremos a capacidade de poder:

- designar objetos;

- dizer alguma coisa dos objetos que designamos sob a forma de uma proposição enunciada;

- religar uma proposição enunciada a outras de modo coerente (descrição, inferência...);

- marcar o valor, o modo ou o estatuto acordado a uma expressão por aquele que enuncia (Duval, 2004, p. 88-89).

O Braille é uma língua, pois cumpre as funções discursivas e metadiscursivas apontadas por Duval (2004, p. 88-89). Quando realizamos uma transcrição da tinta para o Braille, operamos uma conversão do tipo tradução, da língua natural para o Braille. É importante salientar que há diferenças profundas em certos elementos gráficos em tinta e no Braille. 
Na sequência, analisamos a conversão do Livro Didático de Matemática em Tinta (LDMT) para o Livro Didático de Matemática em Braille (LDMB) e do Código de Matemática Unificado (CMU) e o que tudo isso pode nos indicar em relação à aprendizagem matemática pelo estudante cego.

\section{Procedimentos metodológicos e resultados obtidos: aumento e disposição espacial dos caracteres em tinta e em Braille}

Utilizou-se a análise documental como forma metodológica para coletar os dados necessários com o objetivo de responder aos questionamentos levantados. Para Lüdke e André (1986, p. 39), os documentos "não são apenas uma fonte de informação contextualizada, mas surgem num determinado contexto e fornecem informações sobre esse mesmo contexto".

Estudamos a $6^{\mathrm{a}}$ unidade do livro didático do Sistema de Ensino Positivo (Campagnaro, 2012), $9^{\circ}$ ano do Ensino Fundamental que contém 26 páginas, numeradas de 18 a 43, as quais foram transcritas para o Braille (Campagnaro, 2014) e que passam a ter 52 páginas, numeradas de 39 a 90 . Observamos, de imediato, um aumento significativo no número de páginas. Adianta-se que esta constatação se deve em muito por conta da presença de expressões matemáticas, uma das razões da escolha desta unidade para este estudo que focará questões relacionadas à transcrição da escrita do CMU. Uma diferença significativa entre um e outro, além do número de páginas, para o caso do livro de matemática, é o tamanho das obras: enquanto que o LDMT possui as dimensões $20 \mathrm{~cm}$ por $27 \mathrm{~cm}$ e $1 \mathrm{~cm}$ de espessura, o LDMB mede $29,5 \mathrm{~cm}$ por $30 \mathrm{~cm}$ e $5 \mathrm{~cm}$ de espessura; um aumento importante no tamanho que pode até dificultar o seu manuseio pelo estudante cego que, algumas vezes, precisa levar o livro para casa.

Inicialmente, mostraremos os resultados em relação à análise do CMU. O fenômeno da não congruência semântica verificada no CMU foi percebido quando se transitava entre os símbolos matemáticos em tinta para o Braille. O ponto preocupante e que poderia se mostrar como um empecilho para a aprendizagem do estudante cego trata-se da diferença na quantidade e da disposição espacial de símbolos em expressões matemáticas encontrados em tinta em comparação às expressões escritas em Braille.

Verificando a diferença comentada anteriormente, fizemos a análise no CMU focando principalmente nas páginas com expressões algébricas. Apresentamos no Quadro 1, a seguir, três expressões da página 51 do CMU que foram selecionadas para a discussão em relação ao aumento na quantidade de símbolos quando da transcrição da tinta para o equivalente em Braille: 
DOI: http://dx.doi.org/10.20396/zet.v24i3.8648092

Quadro 1 - Quantidade de símbolos em tinta e em Braille de algumas expressões matemáticas

\begin{tabular}{|c|c|c|c|c|}
\hline Linha & $\begin{array}{c}\text { Expressões em } \\
\text { tinta }\end{array}$ & $\begin{array}{l}\text { Num. de } \\
\text { símbolos } \\
\text { em tinta }\end{array}$ & Expressões equivalentes em Braille & $\begin{array}{c}\text { Num. de } \\
\text { símbolos } \\
\text { em Braille }\end{array}$ \\
\hline 1 & $\sqrt{x^{2}+y^{2}}$ & 6 & : & 13 \\
\hline 2 & $\sqrt[3]{3 a^{2}-a}+9$ & 9 & 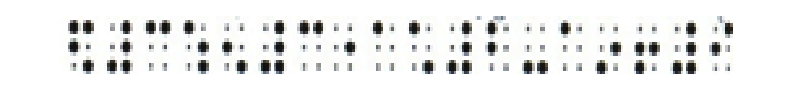 & 18 \\
\hline 3 & $\frac{x^{2}-1}{x^{2}+1}$ & 9 & 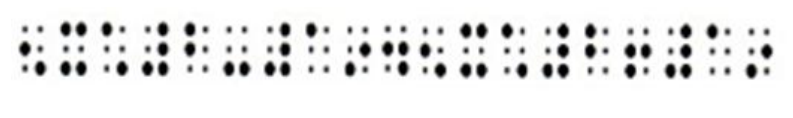 & 19 \\
\hline
\end{tabular}

Fonte: Adaptado de Brasil (2006, p.51).

Tomemos apenas o caso de uma parte de uma das expressões apresentadas: $x^{2}$, presente em $\sqrt{x^{2}+y^{2}}$. Em língua natural, $x^{2}$ é composto por dois símbolos e pela disposição espacial que caracteriza o "2” como expoente; já em Braille, tem-se $x^{2}$ como $\because: \vdots: \vdots: \vdots:$, indicando 4 símbolos dispostos em uma mesma linha. Nesse exemplo, percebemos que não há a possibilidade de uma congruência semântica dos elementos significantes ( $1^{\circ}$ critério de congruência), já que para 2 caracteres em língua natural correspondem 4 caracteres em Braille. Apenas para $x^{2}$ há o acréscimo de 2 caracteres em Braille e, para a expressão como um todo, são acrescidos 7 novos caracteres para o código Braille (de 6 em tinta para 13 em Braille).

Para o estudante cego o funcionamento dos receptores sensoriais táteis implica em um deslocamento contínuo sobre a fonte de estimulação (Nolan e Kederis, 1969) e, o que foi verificado anteriormente quanto ao aumento do número de caracteres, pode deixar a leitura ainda mais lenta e fatigante.

Análise semio-cognitiva de uma expressão algébrica ${ }^{5}$

Uma expressão algébrica pode ser caracterizada pela organização linear de quatro tipos de termos, quer dizer, sendo cada um deles uma unidade elementar de sentido e cuja representação exclusivamente gráfica é um caractere:

1. os termos que designam variáveis;

2. dígitos que designam números;

3. símbolos de operações (a potência é indicada por uma posição deslocada em relação à sucessão linear dos termos);

4. os símbolos de relação entre termos ou entre expressões algébricas (igualdade, desigualdade).

Há ainda um quinto símbolo equivalente à pontuação para marcar as unidades de

\footnotetext{
${ }^{5}$ Esta análise toma por base trocas de e-mails com Raymond Duval em janeiro de 2016.
} 
sentido que não são mais termos, mas a combinação de variáveis ou números com o símbolo de relação.

O Quadro 2, a seguir, resume uma análise semio-cognitiva de uma expressão do tipo presente na linha 3 do Quadro 1.

Quadro 2 - Análise semio-cognitiva da expressão $\frac{x^{2}-1}{x^{2}+1}$ e a expressão equivalente em Braille apresentada na última linha do Quadro 1

\begin{tabular}{|c|c|c|c|}
\hline Escrita matemática & \multicolumn{2}{|c|}{ Conversão } & Codificação \\
\hline $\begin{array}{c}\text { Análise da } \\
\text { organização } \\
\text { sintáxica da } \\
\text { expressão algébrica }\end{array}$ & $\begin{array}{c}\text { Representação não } \\
\text { discursiva da organização } \\
\text { sintáxica }\end{array}$ & $\begin{array}{c}\text { Descrição verbal da } \\
\text { expressão algébrica em } \\
\text { língua natural }\end{array}$ & $\begin{array}{l}\text { Designação oral } \\
\text { de cada caractere } \\
\text { para a } \\
\text { reprodução } \\
\text { escrita da } \\
\text { expressão }\end{array}$ \\
\hline $\begin{array}{l}\text { Dois níveis de } \\
\text { organização }\end{array}$ & $\begin{array}{l}\text { Dois tipos diferentes de } \\
\text { representação não } \\
\text { discursiva }\end{array}$ & $\begin{array}{c}\text { Não congruência com a } \\
\text { ordem no percurso visual } \\
\text { da expressão }\end{array}$ & $\begin{array}{l}\text { Enumeração } \\
\text { seguindo a } \\
\text { ordem de } \\
\text { sucessão dos } \\
\text { termos com a } \\
\text { passagem para a } \\
\text { linha seguinte }\end{array}$ \\
\hline $\begin{array}{c}\text { Razão de duas } \\
\text { expressões } \\
\text { algébricas (quer } \\
\text { dizer, duas } \\
\text { expressões, } \\
\text { algébricas são as } \\
\text { duas unidades de } \\
\text { sentido que são elas } \\
\text { mesmas expressões } \\
\text { algébricas) }\end{array}$ & $\begin{array}{c}\text { Superposição de duas } \\
\text { escritas lineares. Não é uma } \\
\text { organização bidimensional } \\
\text { como uma figura } \\
\text { geométrica, um esquema ou } \\
\text { uma imagem. }\end{array}$ & $\begin{array}{c}\text { Designação da } \\
\text { superposição "embaixo", } \\
\text { "em cima", "dividir por" (o } \\
\text { traço horizontal é um termo } \\
\text { de operação) }\end{array}$ & $\begin{array}{l}\text { Desaparecimento } \\
\text { de toda indicação } \\
\text { sobre a } \\
\text { organização da } \\
\text { expressão pela } \\
\text { simples } \\
\text { enumeração dos } \\
\text { termos }\end{array}$ \\
\hline $\begin{array}{c}\text { As duas expressões } \\
\text { algébricas da fração } \\
\text { são expressões que } \\
\text { pode ser } \\
\text { desenvolvidas } \\
\text { independentes uma } \\
\text { da outra }\end{array}$ & $\begin{array}{c}\text { Árvore ou esquema } \\
\text { representando a ordem das } \\
\text { prioridades das operações e } \\
\text { a propriedade de } \\
\text { distributividade para cada } \\
\text { uma das expressões (aqui } \\
\text { há uma linearização nos } \\
\text { encaixes das expressões) }\end{array}$ & $\begin{array}{l}\text { Designação do termo de } \\
\text { operação que articula um } \\
\text { termo variável e um } \\
\text { número (dois termos de } \\
\text { variáveis de potência } \\
\text { diferente) para formar uma } \\
\text { expressão. Isto é claro para } \\
\qquad(\mathrm{x}+1) .(\mathrm{x}-1)\end{array}$ & $\begin{array}{l}\text { sucessivos, a } \\
\text { proposição } \\
\text { "sobre" } \\
\text { indicando uma } \\
\text { passagem à linha } \\
\text { como em um } \\
\text { ditado de texto }\end{array}$ \\
\hline
\end{tabular}

Fonte: Decorrente de discussões com Raymond Duval por correspondência eletrônica. 
DOI: http://dx.doi.org/10.20396/zet.v24i3.8648092

A escrita em Braille é um código (quarta coluna da tabela) que:

- lineariza a escrita matemática e apaga a sua organização sintáxica não linear;

- cria um custo semiótico de leitura por conta do número de símbolos a serem percorridos e retidos em memória de curto termo.

$\mathrm{Na}$ expressão matemática em tinta, há 9 termos que são símbolos ou caracteres com funções semânticas e sintáticas diferentes (variáveis, operações e números). Já, a sucessão dos 19 caracteres em Braille corresponde:

- um para cada operação. Assim, o traço de divisão, a soma e subtração são representados por caracteres equivalentes em Braille;

- como a expressão $x^{2}-1$ divide $x^{2}+1$, há a necessidade, em Braille, de acrescentar parênteses auxiliares para indicar que a expressão à direita será dividida pela expressão à esquerda. Quando tentamos escrever em tinta a expressão de forma linear, temos: $\left(x^{2}-1\right) /\left(x^{2}+1\right)$. Agora se tentássemos transcrever esta expressão linear para o Braille, além do parêntese usual em tinta, aparecerá um caractere no começo e outro no fim da expressão para indicar que toda essa expressão irá operar. Sendo assim, mesmo na transcrição da forma linear em tinta, os parênteses auxiliares aparecem, pois são de uso exclusivo do Sistema Braille, os quais não são substituídos pela existência dos parênteses que usamos nas expressões em tinta;

- há o acréscimo de 2 caracteres em Braille, um para cada "1" que aparece na expressão, para indicar que são numerais;

- um caractere específico, em Braille, para representar o “2” como expoente.

Tratando-se de expressões algébricas, que não bastam ser lidas para serem resolvidas, após a leitura seria necessário o tratamento das expressões, o que demandaria o uso ainda de mais caracteres, dificultando e aumentando o tempo de resolução de tais expressões.

Tomemos ainda, a expressão da linha 3 da Quadro 1 em um processo de simplificação como mostra o Quadro 3 a seguir: 
DOI: http://dx.doi.org/10.20396/zet.v24i3.8648092

Quadro 3 - Tratamento da simplificação da expressão $\frac{x+1}{x^{2}-1}$ em tinta e em Braille

\begin{tabular}{|c|c|c|}
\hline Passos & $\begin{array}{c}\text { Expressão em } \\
\text { tinta }\end{array}$ & Expressão em Braille \\
\hline I & $\frac{x+1}{x^{2}-1}$ & 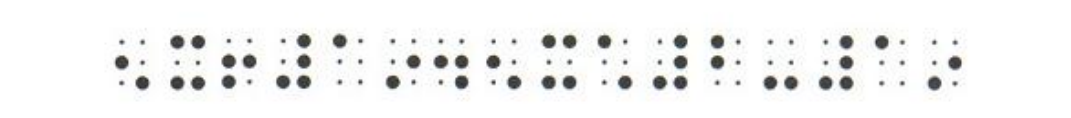 \\
\hline II & $\frac{x+1}{(x+1)(x-1)}$ & 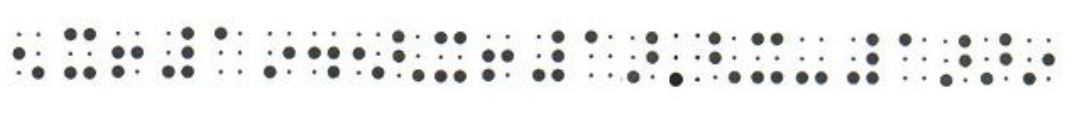 \\
\hline III & $\frac{1}{x-1}$ & 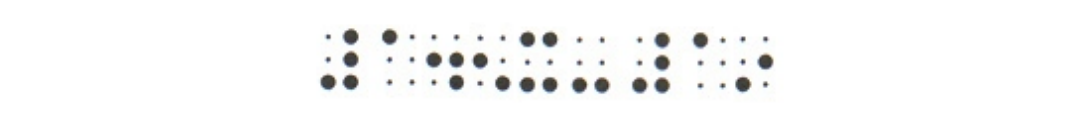 \\
\hline
\end{tabular}

Fonte: Os Autores.

No Quadro 3, os estudantes que enxergam têm a possibilidade de acompanhar de maneira espacial a apresentação de cada passo do tratamento até alcançar o resultado desejado. Esta forma espacial de apresentação das expressões ainda permite a este estudante a manipulação algébrica conhecida em matemática como "cancelamento", em que termos semelhantes presentes simultaneamente no numerador e no denominador da expressão podem ser cancelados desde que não sejam nulos. Agora, imaginemos esta mesma situação para o estudante cego que deverá aplicar o tratamento da maneira indicada na terceira coluna do Quadro 3.

Para o estudante que enxerga, é preciso fatorar a expressão $x^{2}-1$ em $(x-1)(x+1) \mathrm{e}$ perceber que o monômio $(x+1)$ é comum ao numerador e ao denominador. Para o estudante cego o procedimento é o mesmo, a diferença entre ele e o estudante que enxerga, é que o estudante cego, além de ter um número bem maior de caracteres, não tem esta escrita espacial que permite o reconhecimento imediato da fração e dos seus três elementos: traço de fração, numerador e denominador. A frase "o termo de cima deve ser cancelado com o termo semelhante que está embaixo" comumente usada por professores em sala de aula não fará sentido para o estudante cego, pois para ele não há em cima ou embaixo e sim, à direita ou à esquerda do sinal de fração. Dessa forma, percebemos o quanto a forma do registro toma importância fundamental para o tratamento das expressões.

Nas expressões dos passos I, II e III em tinta, no Quadro 3, há 29 caracteres assinalados. Já em Braille, são 50 caracteres, um aumento significativo para o estudante cego decodificar. Além disso, a leitura e execução do procedimento desses passos por este estudante é lenta e fatigante uma vez que se dá de forma linear, da esquerda para a direita na transcrição da tinta ao Braille, a disposição espacial da expressão matemática não é preservada em nenhum dos materiais para o estudante cego: CMU e LDMB.

Outra questão relevante que surge com frequência na transcrição para o Braille, é a escrita em duas ou mais linhas para uma única expressão matemática apresentada em uma Zetetiké, Campinas, SP, v.24, n.3, set./dez.2016, p.395-408

ISSN 2176-1744 
DOI: http://dx.doi.org/10.20396/zet.v24i3.8648092

única linha em tinta. Raramente, em livros didáticos, uma expressão matemática é interrompida e tem continuação na outra linha como ocorre na escrita em Braille. Na Figura 2, a seguir, mostramos um exemplo desta situação.

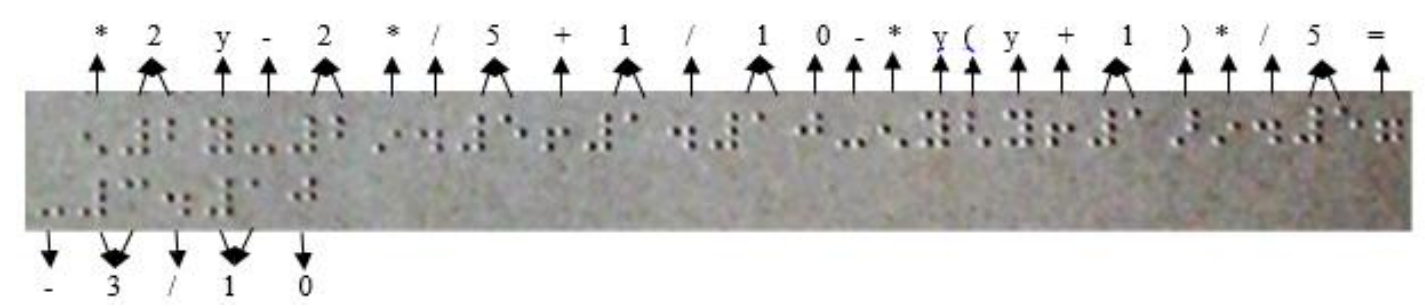

Figura 2 - Transcrição e equivalência dos caracteres de $\frac{2 y-2}{5}+\frac{1}{10}-\frac{y(y+1)}{5}=-\frac{3}{10}$ para o Braille

Fonte: Os autores a partir de Campagnaro (2014, p. 90).

Na Figura 2, os parênteses auxiliares são representados por *, sendo somente utilizados no Sistema Braille, não possuindo nenhum caractere de equivalência em tinta, conforme mencionamos anteriormente. Já para os outros caracteres aparece o representante em tinta, como no caso das operações de subtração e adição e também as letras e numerais.

Conforme já dissemos, além da perda de espacialidade na disposição dos termos matemáticos e do aumento significativo de caracteres em Braille, a expressão, não muito grande escrita em tinta aparece no LDMB em duas linhas.

\section{Considerações Finais}

Observamos na transcrição do LDMT para o LDMB, várias diferenças que podem dificultar a aprendizagem matemática do estudante cego. Conforme apontamos neste texto, há o aparecimento do fenômeno da não congruência semântica em uma situação que não havia: a transcrição para o Braille produz este fenômeno que pode dificultar ou até mesmo impedir a aprendizagem. Tratamos neste trabalho de algumas expressões algébricas para salientar dois aspectos importantes quando da transcrição do LDMT para o Braille: o aumento significativo de caracteres e a perda da espacialidade.

A espacialidade, em particular, nas expressões matemáticas a serem manipuladas é uma criação didática que se mostrou, ao longo de muitos anos, propositiva para o trabalho em álgebra. Observemos, por exemplo, a dificuldade que seria para manipular a expressão da Figura 2 se fosse escrita na seguinte forma para o estudante que enxerga:

$$
(2 y-2) \div 5+1 \div 10-y(y+1) \div 5=-3 \div 10
$$

Estamos convictos que a espacialidade nas expressões matemáticas contribui para a aprendizagem matemática do estudante que enxerga e deve ser mantida na escrita em Braille.

Outo aspecto que tratamos foi o aumento significativo do número de caracteres na transcrição para o Braille. Esse aumento introduz, também, o fenômeno da não congruência 
semântica. Se na transcrição para o Braille pudesse ser mantido a espacialidade das expressões, só neste caso já haveria uma diminuição do número de caracteres em Braille: por exemplo, os 4 parênteses acrescidos na escrita em Braille da expressão da terceira coluna do Quadro 1 seriam dispensáveis. Uma vez que o caractere que representa um numeral coincide com o caractere que representa uma letra (por exemplo, " 1 " e "a" coincidem na escrita em Braille), em uma expressão algébrica, há a necessidade de indicar que um numeral que aparece é mesmo um numeral e não uma letra, isso é repetido tantas vezes quanto forem os numerais na expressão. Haveria outro modo de fazê-lo?

Acreditamos que o LDMB deve ser diretamente pensado para o estudante cego, não proposto a partir de uma transcrição direta de algum livro didático dedicado ao estudante que enxerga como foi o caso que expusemos aqui e que é, em geral, o que acontece.

Essas diferenças semio-cognitivas que surgem quando da transcrição da tinta para o Braille, no caso das expressões matemáticas, quanto à forma dos registros e o aumento de caracteres fazem parte do princípio de um estudo que pretendemos levar adiante com outros tópicos em matemática, como por exemplo: o papel das figuras geométricas na aprendizagem da geometria pelo estudante cego; o papel da descrição de imagens, figuras ou fotos em Braille para a aprendizagem matemática; o funcionamento do sistema cartesiano em Braille; o acesso em Braille ao gráfico de funções, etc.

\section{Referências}

Anjos, D. Z. dos. (2008). Tenho um Aluno Cego, e Agora? Monografia Licenciatura em Matemática. Florianópolis: Universidade Federal de Santa Catarina. Retirado em 10 de janeiro, 2016, de: https://repositorio.ufsc.br/handle/123456789/96594.

. (2014). CMU - Código Matemático Unificado para a Língua Portuguesa: uma análise de seu uso pelo professor de matemática. In: Colóquio Internacional "Educação e Contemporaneidade", VIII, 2014, Sergipe. Anais: Colóquio Internacional "Educação e Contemporaneidade", VIII. EDUCON, Sergipe. (pp. 1-11). Retirado em 15 de janeiro, 2016, de: http://educonse.com.br/viiicoloquio.

- (2015). Da Tinta ao Braille: estudo de diferenças semióticas e didáticas dessa transformação no âmbito do Código Matemático Unificado para a Língua Portuguesa - CMU e do Livro Didático em Braille. Dissertação em Educação Científica e Tecnológica. Florianópolis: Universidade Federal de Santa Catarina. Retirado em 15 de janeiro, 2016, de: https://repositorio.ufsc.br/handle/123456789/135381.

Brandt, C.F.; Moretti, M.T. (2013). Algumas Considerações sobre o ensino do sistema de numeração: discussão de atividades à luz da conceitualização e representação semiótica. Espaço Pedagógico, Passo Fundo, n. 1. (pp. 54-75). Retirado em 16 de janeiro, 2016, de: http://upf.br/seer/index.php/rep. 
DOI: http://dx.doi.org/10.20396/zet.v24i3.8648092

Brasil (2006). Ministério da Educação. Secretaria de Educação Especial. Código Matemático Unificado para a Língua Portuguesa. Elaboração: Jonir Bechara Cerqueira et al. Brasília: MEC/SEESP.

- (2013). Ministério da Educação. Secretaria de Educação Básica. Diretrizes Curriculares Nacionais da Educação Básica. Brasília: MEC/SEB/DICEI.

Campagnaro, M.F.M. (2012). Matemática: $9^{\circ}$ Ano. Curitiba: Positivo.

. (2014). Matemática: $9^{\circ}$ Ano. Transcrição em Braille: CAP/Florianópolis. Curitiba: Positivo.

Duval, R. (2003). Registros de Representação Semiótica e Funcionamento Cognitivo da Compreensão em Matemática. In: Machado, S.D.A. de (Orgs.). Aprendizagem em Matemática: Registros de Representação Semiótica. (pp. 11-33). Campinas: Papirus.

- (2004). Semiosis y pensamiento humano: registros semióticos y aprendizajes intelectuales. Tradução Myrian V. Restrepo. Colômbia: Universidad del Valle.

. (2011). Ver e Ensinar Matemática de outra Forma. Entrar no modo matemático de pensar: os registros de representação semióticas. Tradução Marlene A. Dias. São Paulo: PROEM.

- (2012). Registros de representação semiótica e funcionamento cognitivo do pensamento. Trad. de M. T. Moretti. Revemat, Florianópolis, v. 7, n. 2. Retirado em 20 de janeiro, 2016 de: http://www.periodicos.ufsc.br/index.php/revemat.

Fernandes, S. H. A. A.; Healy, L. (2007). Transição entre o Intra e o Inter Figural na construção de conhecimento geométrico por estudantes cegos. Educação Matemática em Pesquisa. São Paulo, v. 9, n.1. (pp. 121-153).

. (2010). A Inclusão de Alunos Cegos nas Aulas de Matemática: explorando Área, Perímetro e Volume através do Tato. Bolema. Rio Claro (SP), v. 23, n.37. (pp. 11111135).

Lüdke, M.; André, M. (1986). Pesquisa em Educação: Abordagens Qualitativas. São Paulo: EPU.

Machado, R. do C. (2009). Descomplicando a escrita Braille: considerações a respeito da deficiência visual. Curitiba: Juruá.

Mello, E.M. (2012). Um estudo das dificuldades enfrentadas por deficientes visuais com as representações matemáticas. In: Encontro de Produção Discente PUCSP/Cruzeiro do Sul, São Paulo. (pp. 1-7).

Moretti, M.T.; Thiel, A.A. (2012). O ensino de matemática hermético: um olhar crítico a partir dos registros de representação semiótica. Práxis Educativa (UEPG. Online), v.7, (pp.379-396). 
DOI: http://dx.doi.org/10.20396/zet.v24i3.8648092

Nolan, C.Y.; Kederis, C.J. (1969). Perceptual factors in Braille Word recognition. New York: American Foundation for the Blind.

Peirce, C.S. (2000). Semiótica. Tradução de J. T. Coelho Netto. São Paulo: Perspectiva.

Saussure, F. de. (2008). Curso de linguística geral. Tradução de A. Chelini, J. P. Paes, I. Blikstein. São Paulo: Cultrix.

Uliana, M.R. (2013). A Inclusão de alunos cegos nas aulas de matemática das escolas públicas estaduais de Rondônia. In: Encontro Nacional de Educação Matemática, XI, 2013, Curitiba. Anais: Encontro Nacional de Educação Matemática, XI, ENEM. Curitiba. (pp. 1-15).

Unesco. (1994). Declaração de Salamanca sobre princípios, política e práticas na área das necessidades educativas especiais. Salamanca: Unesco. 